\title{
Analyzing the Impact of Climate Change on Cotton Yield Using Spatial Analysis and Statistical Modeling in the Indus River Basin, Pakistan
}

\author{
Naveed M1, He HS' ${ }^{2}$, Yasir QM1, Du H$^{1}$ and Satti $Z^{1}$ \\ ${ }^{1}$ Key Laboratory of Geographical Processes and Ecological \\ Security of Changbai Mountains, Ministry of Education, \\ School of Geographical Sciences, Northeast Normal \\ University, Changchun, People's Republic of China \\ ${ }^{2}$ School of Natural Resources, University of Missouri, \\ Columbia, MO, USA
}

*Corresponding author: Hong S He, School of Natural Resources, University of Missouri Columbia, MO 65203, USA

Received: J une 28, 2021; Accepted: July 23, 2021;

Published: July 30, 2021

\begin{abstract}
Cotton is an excessive growing fiber crop in the world. In Pakistan, climate warming is hurting the cotton crop. To identify countermeasures of climate change impacts on crop production, it is needed to explore the changes in crop yield and their relationship to climate change. This study, we conducted spatial analysis of cotton yield and climate data in the Indus River basin in Pakistan from 19892018. We analyzed the trend in cotton production indices and climate variables using the Mann-Kendal nonparametric test, and the impact of climate change on cotton yield through Pearson's correlation and best-subset multivariate linear regression model. Sunshine hours positively impacted on cotton yield, but an increasing trend in average temperature, minimum temperature and air relative humidity in main crop areas had a negative impact on the cotton crop. Our results illustrate the relationship between the cotton yield and climate change variables on regional basis in the Indus River basin, Pakistan. This research could provide a reference for understanding the intolerance of cotton in the Indus River basin, Pakistan to climate change.
\end{abstract}

Keywords: Climate change; Cotton; GIS; Multivariate regression

\section{Abbreviations}

AIC: All-Subset Information Criteria; BIC: Bayesian Information Criteria; GIS: Geographic Information System; MMK: Modified Mann-Kendal; MLR: Multivariate Linear Regression; RMSE: Root Mean Square Error

\section{Introduction}

Cotton is one of the major cash crops worldwide and the natural fiber crop in textile industries [1,2]. Cotton is also fine chemical raw material and an oil crop [3] planted in more than 80 countries around the world [4]. Cotton cultivation is thoroughly linked to climatic conditions and irrigation and greatly influences total nitrogen emissions during the growing period [5]. Thus, timely and efficient data of the spatial distribution of cotton is vital for agricultural management, regional crop response, and agricultural policymaking under climate change [6]. Cotton is successfully grown at temperatures ranging from $28.20^{\circ} \mathrm{C}$ in China to $41.80^{\circ} \mathrm{C}$ in Sudan. Seasonally, average temperatures are about $36.80^{\circ} \mathrm{C}$ in the Indus River basin, Pakistan. However, history exhibits that heat stress is a major obstacle to cotton growth in some states, including Pakistan, Syria and India. Moreover, the increase in temperature can hurt the budget of cotton in regions where it is already grown at a temperature of almost $40^{\circ} \mathrm{C}$ [7]. Pakistan is fourth largest cotton producer in the world [8]. Indus River basin cotton belt covers the $88 \%$ of the cotton crop area and $90 \%$ of the cotton production of Pakistan (Pakistan Bureau 2018), which has low seasonal rainfall and high temperatures.

Climate change has been one of one of the most important issues affecting many systems [9]. It is estimated that anthropogenic activities caused about $1^{\circ} \mathrm{C}$ global warming at pre-industrial levels [10]. Under various emission scenarios, the projected increase ranges from $2^{\circ} \mathrm{C}$ to $5^{\circ} \mathrm{C}$ by the end of the twenty-21 century [11]. The global climate system and agroecology have already and will continue to analyzing impact of warming, e.g., [12,13]. For the past several decades, scientists have been investigating the influences of climatic variations on the cotton yield. Daily minimum and maximum temperature have been examined that extreme weather events have adverse effects on ecological systems [14]. Rosenzweig et al. studied that climate change is expected to increase the vulnerability of agricultural systems by changes in rainfall patterns. Increasing temperature and increased frequency of extreme weather events in most parts of the world [10] especially in Pakistan [15,16]. Arid to semi-arid regions [15,17-19] are expected to have a negative impact on crops due to projected changes. Increases in temperature [20] and changes in precipitation have a negative impact on cotton growth and productivity [21,22]. The optimum temperature for efficient growth is reported to be $33^{\circ} \mathrm{C}$, whereas substantial reduction in flower and boll retention has been recorded when temperature is above $36^{\circ} \mathrm{C}[16,23,24]$. Variation in temperature have a significant impact on cotton growth and seed cotton production $[25,26]$. The boll growth period shortens with high temperatures, resulting in a smaller boll and reduced cotton output $[27,28]$. Temperature and air humidity are the main factors that affect cotton growth [29]. Using statistical approaches, researchers from different countries investigated the influence of climate change on cotton crop. Tang Xiang-ling and Xin [30] used Multivariate Linear Regression (MLR) analysis to analyze climate and cotton yield variations in Shiheze, China. They have found that cotton production has been improved by an increase in temperature, sunshine, and precipitation. Chao et al. used a provincial-based study and observed that variations in temperature, air and precipitation had a positive 
effect on cotton productivity. Turner et al. observed that yield of cotton is directly influenced by temperature. Deng Zhenyong et al. [29] analyzed the impact of global warming on various crops in the northwest region of China and found that global warming had a major impact on crop yield as it enhances the production of thermophilic crops (cotton) and changes the growth period of the crops. These adaptive modifications support crops gain additional heat and light for photosynthesis thus helps in the aggregation of dry matter [29]. Moreover, irregular spatiotemporal distributions of precipitation may adversely affect cotton yield [31]

However, the actual climate change varies significantly among regions, which can greatly affect a crop yield. Furthermore, climate conditions are different on different sites in the same region that affect the crop yield [32]. Therefore, the impact of climate change on cotton yield at different locations should be considered to make efficient use of climate resources at specific sites, which can guide to improve plant structures and yield management. Most of the previous studies investigating the impact of climate change on crop production have been focused on grain crops such as rice, corn, and wheat. Although some researchers have examined the influences of climate change on cotton growth and production, the majority of these studies were based on a single site $[30,32,33]$, with very few including multiple locations at regional scales [34]. In addition, these studies did not examine the impact of multiple climate factors on cotton yield based on an assessment of simple correlation and multiple linear regressions.

Pakistan has an arid to semiarid climate with great variability in temperature, with diversified topography and an extremely variable climate. The study of vegetation and moisture stress clearly shown that stress on soil moisture increased in Kalat region of Pakistan that ultimately leads to aridity $[9,35]$. Pakistan has a diverse and extensive agricultural resource base that spans multiple ecological and climatic zones, with substantial potential for producing a variety of foods and fibers [35]. The cotton cultivation belt along the Indus river irrigation system was recognized as the backbone of the economy for the country [36]. Cotton is commonly known as "white gold," an important cash crop for Pakistan and grows typically in agricultural plains of the Indus River basin. It contributes $18.5 \%$ of the value-added share in national agriculture and about $4.5 \%$ to GDP; around two-thirds of the country's export earnings come from the cotton made-up and textile, which adds over $\$ 3.4$ billion to the national economy; while hundreds of ginning factories and textile mills in the country depends upon cotton. Primarily millions of farmers are dependent on this crop, in addition to millions of people employed along the entire cotton value chain, from weaving to textile and garment exports. Climate warming has greatly affected agricultural activities in Pakistan. An increase in temperature observed in the country, especially during the last few decades it is very sharp [37]. This higher temperature rises and other alterations in climatic variables have influenced the development of Pakistan's cotton [7].

In this study, we intend to assess the influence of climatic changes on yield in the Indus river basin, Pakistan. The purpose of this study is to: (1) Analyze changes in climate variables and cotton yield indicators in various sites of Indus River basin, Pakistan, from 1989 to 2018; (2) Describe the relationship and impact of climate variables on cotton yield. This study helps to understand the influence of climatic variability on cotton yield at 12 different sites of the Indus River basin.

\section{Methods}

\section{Study area and datasets}

Southern Pakistan, specifically the cotton belt area in the Indus River basin, is an important physiographic unit that almost produces $85 \%$ of the total cotton crop of Pakistan; and also plays a vital role in the economy of the country (Figure 1). The entire region covers approximately $142075 \mathrm{~km}^{2}$, which is $18 \%$ of the area of Pakistan. Geographically, it extends from $24^{\circ} 56^{\prime} 48^{\prime \prime}$ to $31^{\circ} 57^{\prime} 31^{\prime \prime}$ North latitude and $69^{\circ} 13^{\prime} 5^{\prime \prime}$ to $72^{\circ} 55^{\prime} 41^{\prime \prime}$ East longitude, agricultural activities mostly depend upon irrigation [35]. Physically, soil changes from clay loam to sandy with clay dominant towards the south, in terms of elevation, while going from north to south, the elevation decreases. The study area lies in humid, hot, and dry regions where cotton is cultivated [9]. The uppermost temperatures are measured up to maximum from $45^{\circ} \mathrm{C}$ to $50^{\circ} \mathrm{C}$. Because of very short rainfall ( 155 to $755 \mathrm{~mm}$ ), cotton production is relying on irrigation as the cotton plants need less water compared to sugarcane and rice.

The monthly cotton-growing season (May-September) weather data from 1989 to 2018 at 12 meteorological centers in the Indus River basin were collected from the regional offices of the Pakistan Meteorological Department (http://www.pmd.gov.pk) and the cotton index data of the selected stations were collected from Pakistan Bureau of Statistics (http://www.pbs.gov.pk). The climate variables included $T_{\text {max }}, T_{\text {min }}, T_{a v e}, P_{r e}$, sunshine duration, and air relative humidity, which is the variable in space and time that may affect the yield of cotton, verifying the need to examine the influence of climate on cotton production [38]. In the Indus River basin, cotton is planted at the end of April and the start of May and cropped once a year. After 6 days of the plantation, seedlings appear; budding begins from the end of June; cracking starts in the middle of July to the start of August; and finally, growth stops at the end of September. May to September is a cotton-growing season that covers 150-170 days in Table 1.

\section{Spatial analysis of change in cotton and climatic variables}

In this study, trends were analyzed using the Modified MannKendall (MMK) method [39] based on the original non-parametric Mann-Kendall approach [40,41]. MMK statistic is preferred in investigating the climatic changes and trends because it considers the auto-correlation effect and does not require the dataset to be normally distributed, it has low sensitivity to abrupt break due to inhomogeneous time-series [39]. Huang and Li [33] used the MMK test for demonstrating the trends in climate variables in oases of the arid region of China from 1981-2012 and [42] conducted the rainfall trend analysis for the period 1968-2010 using linear regression analysis and MMK test. The MMK statistic $Z_{c}$ was applied robustly to test the trend in the time series of climate variables and cotton indices from 1989 to 2018 at 12 sites. The hypothesis that $S=0$ is accepted using a two-tailed test. The Non-parametric test has more potential than parametric when the probability distribution of data is biased [43]. MMK test is preferred when various sites are tested in a single study [44].

We processed the climate and cotton data (Table 1) in ArcGIS. Kriging geostatistical method was used to generate an estimated surface from a scattered set of points containing different values. It 
Table 1: The average cotton index, climate variables of cotton growth season (May-Sep) and site information in Indus River basin Pakistan.

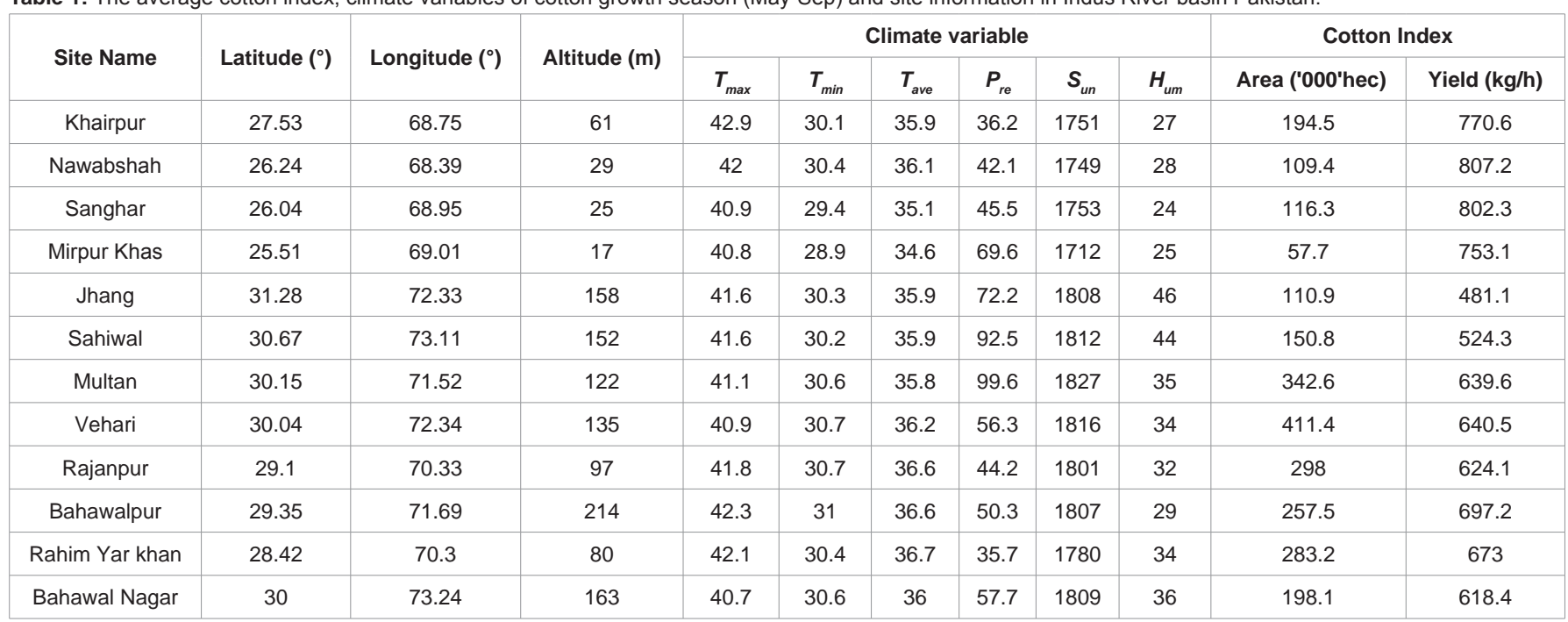

Note: Climate variable: $T_{\max }$ : Maximum Temperature; $T_{\min }$ : Minimum Temperature; $T_{\text {ave }}$ : Average Temperature; $P_{r e}:$ Precipitation; $S_{u n}:$ Sunshine Hour; $H_{u m}:$ Average Air Relative Humidity.

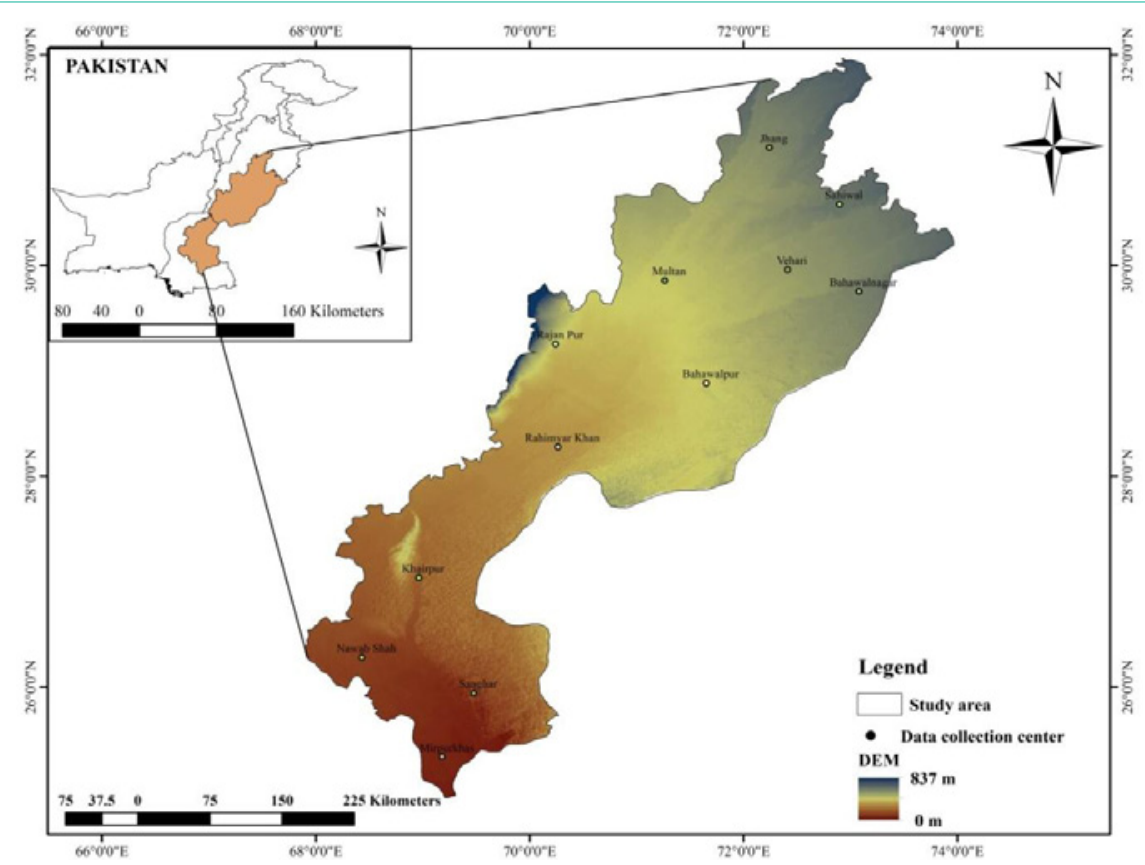

Figure 1: Study area map indicating the crop and metrological data collection center in Indus River basin, Pakistan.

effectively involves an interactive investigation of the spatial behavior of the phenomenon represented by different values and this technique not only has the capability of producing a prediction surface but also provides an accuracy of the prediction. The interpolation method assumes that the distance or direction between sample points reflects a spatial correlation that was used to explain the variation in the surface. This technique was used for visualization, precise understating, thematic mapping, and spatial distribution of change in climate variables, and the cotton index was mapped site-specifically using ArcMap 10.5 software.

\section{Influence of climatic changes on cotton yield}

We used the multivariate linear regression (MLR) function, and the Best-Subset Selection (BSS) method to further describe the relationship between crop yield and climatic variables. This MLR function, forced through the origin, was written as follows [45].

$$
\Delta \mathrm{Y}=\lambda_{\mathrm{i}} \Delta \mathrm{X}
$$

Where $\Delta \mathrm{Y}$ is the first-order difference of the cotton yield index $\lambda_{\mathrm{i}}$ shows the standardized regression coefficients, $\Delta \mathrm{X}$ is the firstorder difference of the key climate variables $(i=1,2, \ldots, 6)$. The standardized coefficients have been used to study the impact of the variables when variables are measured on a different scale [46]. Analyzing the influence and strength of the relationship between the climate variable and the cotton yield in North China from 19812012 [47] were used correlation coefficient and MLR analysis. Their 

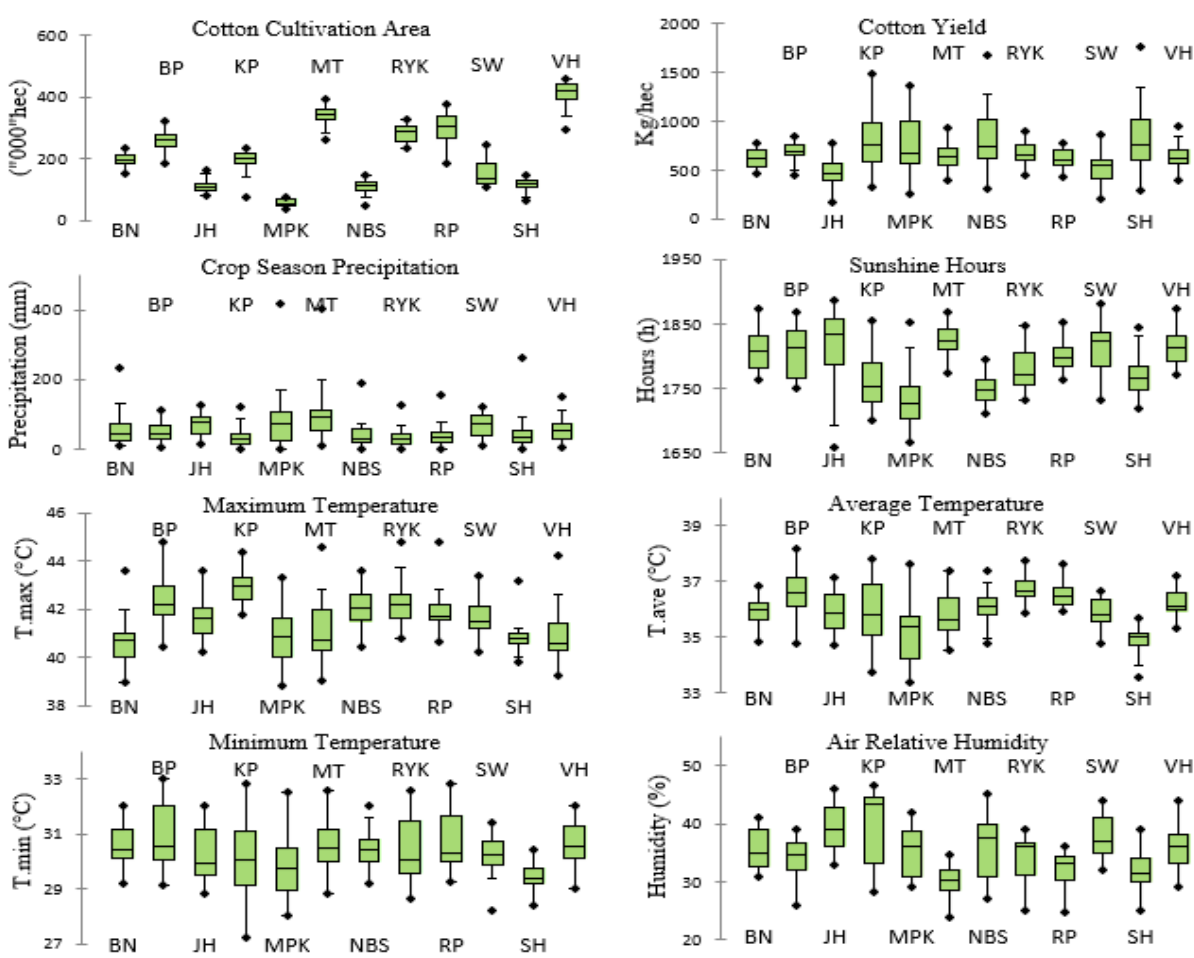

Figure 2: Box plots of the climatic variables and cotton indices during cotton growth season over 1989 - 2018 at 12 sites BN-Bahawalnagar, BP-Bahawalpur, JHJhang, KP-Khairpur, MPK-Mirpur khas, MT-Multan, NBS-Nawabshah, RYK-Rahim yar khan, RP-Rajanpur, SW-Sahiwal, SH-Sanghar and VH-Vehari in Indus basin River, Pakistan. Horizontal line: median; box-boundaries: $25^{\text {th }}$ and $75^{\text {th }}$ percentiles; whiskers: $10^{\text {th }}$ and $90^{\text {th }}$ percentiles; circles outliers.

outcomes suggested that warming enhanced the growth of cotton and the progression of the cotton phenomenon, but shortened the period of cotton growth. The environmental factor, including climate and non-climatic factors and location; are the leading causes of inter-annual alterations in crop growth. Thus, it is obligatory to eliminate the confounding effect of non-climatic factors $[45,48]$. This method reduces the impacts of varieties, management factors, and fertilizers to describe the annual crop growth against climate $[38,49]$. The regression equations between cotton yield and climate variables $\left(T_{\max }, T_{\text {min }}, T_{a v e}, P_{r e}, S_{u n}\right.$ and $\left.H_{u m}\right)$ were selected by the BSS regression method. The best-subset selection method can select the best combination of descriptors from the group of independent variables, as all combinations are examined by [50]. In an attempt to decide on the particular subset to be used, many statisticians consider evaluating all possible regressions and then based on some measured of the subset regression, attempt to reach a decision [51]. In this method, the possible number of the prediction models that would be $2^{\mathrm{k}}$, where $\mathrm{k}$ is the number of independent variables $[52,53]$. For measuring the monthly climate variable's impact on cotton yield, the number of independent variables was thirty. Gorman and Toman proposed that $\left(k_{1} p\right)$ possible regressions of size $\mathrm{p}$ subset that will be considered to be good regression when $\mathrm{k}>10$. By using the adjusted coefficient of determination, $\left(\mathrm{R}_{\text {adj }}^{2}\right)$ model stability was assessed. The model with greater the $\mathrm{R}^{2}$ adj values, has more stability at a significant level [54]. Root Mean Square Error (RMSE) was used to assess the predictive ability of the model. Liu et al. recommended that subset having minimum RMSE and large $\mathrm{R}_{\text {adj }}^{2}$ being considered as best. Pearson correlation was established between pairs of the first-order difference in cotton yield indices and climatic variables during the growing season $[55,56]$. The values of the correlation coefficients essentially represented the climate variables that were meaningful for cotton production at a certain level of significance. Statistical calculations were performed by the XLSTAT software package.

\section{Results}

\section{Temporal and crop-related variations and trends}

All climate variables and crop-related variables fluctuated within ranges of maximum $39-44{ }^{\circ} \mathrm{C}$, minimum $25-32{ }^{\circ} \mathrm{C}$, average temperature $34-38{ }^{\circ} \mathrm{C}$, precipitation $5-455 \mathrm{~mm}$, sunshine hours 1658-1865 $\mathrm{h}$ and air humidity $24-48 \%$ and the variation in cotton cultivated area and yield across the different sites of Indus River basin during the past 30 years can be observed (Figure 2). More fluctions in $T_{a v e}, T_{\min }$ and $H_{u m}$ have been noted in often plases. Especially in Nawabshah, Mirpur, Khairpur, Rajanpur, Bahawalpur, Vehari, Multan. Similarly, Khairpur, Mirpur, Nawabshah, and Sanghar areas have seen more variations in cotton yield. Temperature and air relative humidity at different sits shows a significant variation. Almost all sites recorded a low precipitation trend of less than $100 \mathrm{~mm}$ as well as some extreme events occur at four main cotton cultivated sites. $T_{\min }, T_{a v e}$ and $S_{u n}$ increased significantly in almost all the study sites (Figure 3). Two sites Sahiwal and Rajanpur shows a significant decrease in precipitation trends, while significant increase trend observed in humidity at Multan, Vehari, Jhang, and Sahiwal which is the main cotton cultivation area. The cotton crop cultivated area decreased significantly at three sites in the north of the study area, which is related to Punjab province. Cotton yield shows a significant 

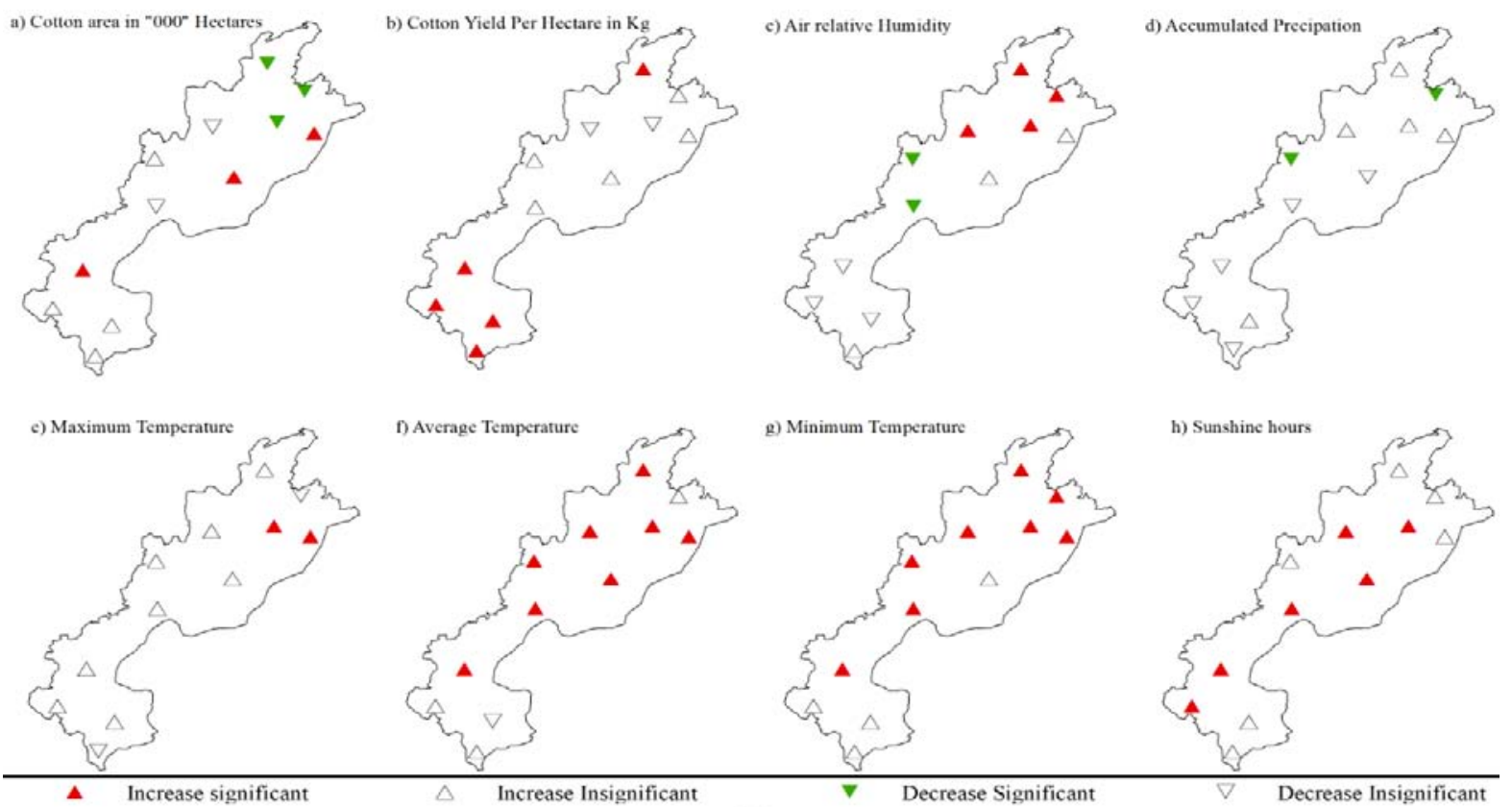

Figure 3: Spatial distributions of trend and significance of the climatic and cotton variables averaged for the cotton growth season for the 12 study locations considered over 1989-2018.
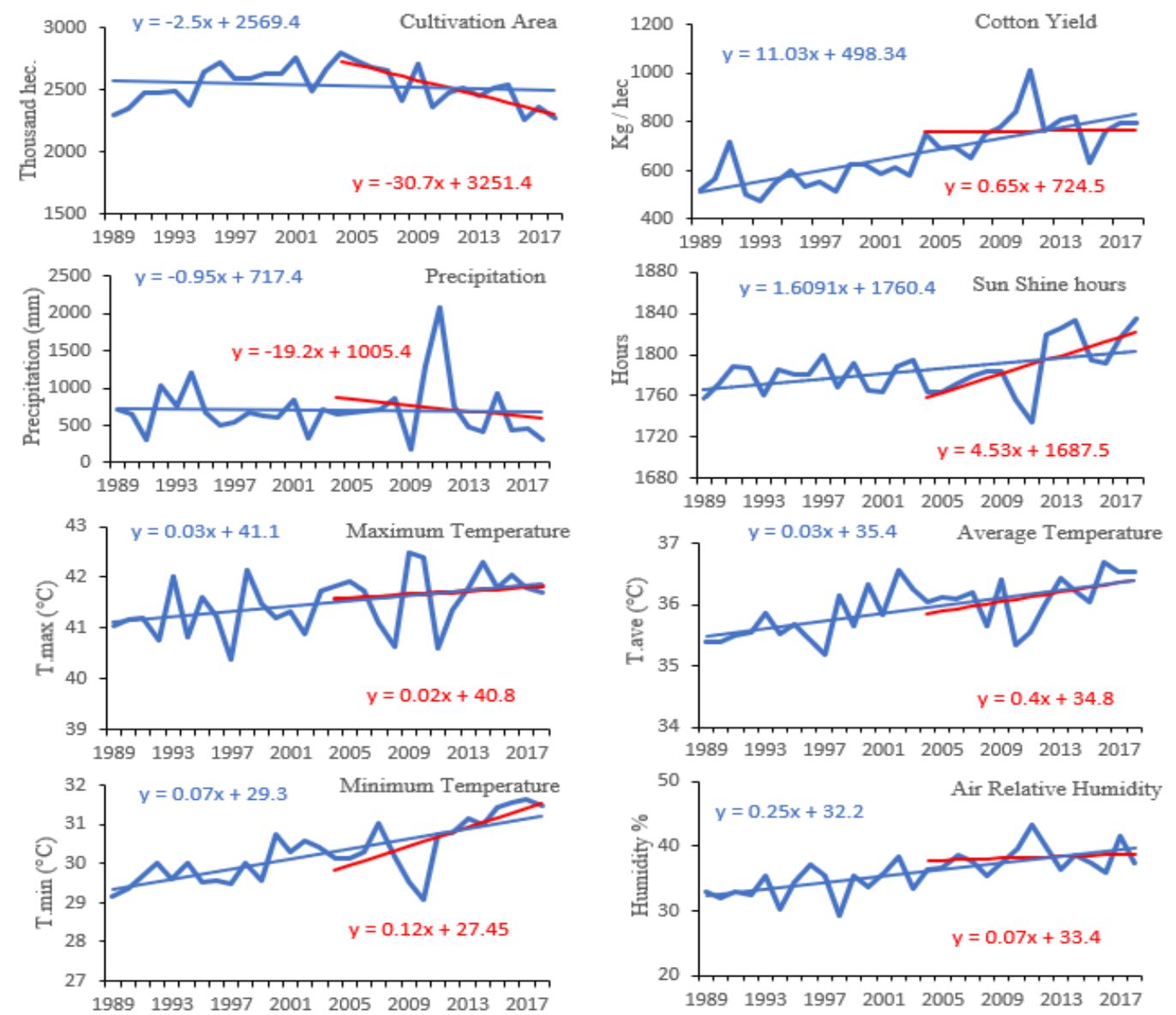

Figure 4: Linear trend tines of cotton indices and climate variables. Blue lines show trends in variables from 1989-2018 while rend lines from 2004-2018. 
Table 2: Single variable fitted equation for $\Delta Y$ and their performance at the Sanghar site.

\begin{tabular}{|c|c|c|c|c|}
\hline Climate Variable & Equation & $\mathbf{R}_{\text {adj }}^{2}$ & RMSE & P-value \\
\hline 1 & $\Delta Y=0.21 \Delta T_{\max }$ & 0.01 & 327.3 & $<0.30$ \\
\hline 2 & $\Delta Y=-0.39 \Delta T_{\min }$ & 0.122 & 308.4 & $<0.05$ \\
\hline 3 & $\Delta Y=-0.63 \Delta T_{\text {ave }}$ & 0.372 & 260.8 & $<0.0001$ \\
\hline 4 & $\Delta Y=0.51 \Delta P_{r e}$ & 0.231 & 288.5 & $<0.005$ \\
\hline 5 & $\Delta Y=-0.02 \Delta S_{u n}$ & -0.035 & 334.7 & $<0.90$ \\
\hline 6 & $\Delta Y=0.07 \Delta H_{u m}$ & -0.026 & 333.2 & $<0.7$ \\
\hline
\end{tabular}

increasing trend at all four sites in the south of the study area, which are located in Sindh province.

To observe the fluctuations in cotton yield, area, and trends of climate change during crop season in study area during past thirty years, trends lines have been drawn. Cotton crop area and precipitation shown decline while the rest have been increasing. To know more about the trends of change, a fifteen-year trends line has also been drawn in which the minimum temperature, crop area and yield rapidly changing trends have been observed Figure 4 .

\section{Selection of the best equation}

To describe the selection procedure of the best equation we performed a single variable regression for the study site Sanghar was selected (Table 2). The equation namely, $\Delta \mathrm{Y}=-0.63 \Delta T_{\text {ave }}$ was found to be the best with the largest $\mathrm{R}_{\text {adj }}^{2}$ and the smallest RMSE value among the six equations. Furthermore, the MLR method on the basis of Pearson's correlation is shown to be a key parameter in the cotton index was performed for cotton yield with the $2,3-, \ldots$ to 6 variables respectively. Finally, equation $\Delta \mathrm{Y}=0.71 \Delta T_{\max }+0.24 \Delta T_{\min }$ $-0.72 \Delta T_{\text {ave }}+0.56 \Delta P_{r e}+0.28 \Delta S_{u n}$ was selected as the best among the all-possible subsets equations for Sanghar. Only the key climate variables that may significantly impact cotton yield were selected through this process, and the other variables were eliminated.
Similarly, this procedure was repeated for all 12 study sites for the selection of the best multivariate regression equations for monthly climate variables and their statistical properties are described (Table 3). For viewing the impact of climate variables on cotton yield in the growing season, the best fitted MLR models standardize coefficients were plotted in (Figure 4).

These standardized coefficients bar show the direction and strength of the climate variables that significantly impact cotton yield.

\section{Intersection between cotton yield and climate variables}

Negative correlation between cotton yield and climate variables has been found in most sites during cotton crop season months. In arid areas, there is positive and negative correlation mix in different months. While in the upper areas where the humidity is high, the negative correlation is more noticeable. In Multan, Vehari, Jhang, and Sahiwal, air humidity, precipitation, and minimum temperature were negatively correlated with cotton yield especially in May and June. While Nawabshah, Sanghar, and Khairpur areas show positive correlation with Tave and Sun in June and July Figure 6.

\section{Discussion}

Spatial analysis of the cotton yield and climate variables on all selected sites of the Indus River basin provides us a clear picture of the behavior of these variables during the past 30 years. Overall decreasing trends have been recorded in rainfall during the past three decades in Pakistan [57]. Our results also show decreasing trends in precipitation at most of the sites, especially in the past fifteen years it shows clear decreasing trend. Temperature analysis showed a consistent pattern of warming across the selected cities of Punjab, Pakistan [58]. A significant increasing trend in temperature at most of our study sites can be observed. There is a significant decrease in the cotton-cultivated area at the three North sites of the study area and a significant increase in cotton yield reported in the Southside of the study area. These results may indicate the shifting of the cotton-

Table 3: For the cotton growing, season (May-September) the best-fitted multivariate linear regression equation and statistical results of all selected sites.

\begin{tabular}{|c|c|c|c|c|}
\hline Site Name & Equation & $\mathbf{R}_{\text {adj }}^{2}$ & RMSE & P-Value \\
\hline Khairpur & $\begin{aligned} \Delta Y= & 0.26 \Delta T_{\max }(\text { May })+0.19 \Delta T_{\max }(\text { June })-0.41 \Delta T_{\max }(\operatorname{Sep})+0.33 \Delta T_{\text {ave }}(\text { May })- \\
& 0.53 \Delta S_{u n}(\text { Aug })-0.51 \Delta H_{u m}(\text { May })-0.57 \Delta H_{u m}(\text { Aug })+0.20 \Delta H_{u m}(\operatorname{Sep})\end{aligned}$ & 0.89 & 88.9 & $<0.0001$ \\
\hline Nawabshah & $\begin{array}{c}\Delta Y=-0.41 \Delta T_{\max }(\text { Aug })+1.27 \Delta T_{\max }(\operatorname{Sep})-0.84 \Delta T_{\text {ave }}(\operatorname{Sep})+0.30 \Delta P_{\text {re }}(\text { May })+ \\
\quad 0.32 \Delta S_{u n}(\text { June })-0.35 \Delta S_{u n}(\operatorname{Sep})-0.72 \Delta H_{u m}(\operatorname{Sep})+0.42 \Delta H_{u m}(\operatorname{Sep})\end{array}$ & 0.82 & 124.8 & $<0.0001$ \\
\hline Sanghar & $\begin{array}{c}\Delta Y=0.56 \Delta T_{\max }(\text { June })-0.45 \Delta T_{\text {ave }}(\text { June })-0.28 \Delta T_{\text {ave }}(\text { July })-0.38 \Delta P_{r e}(\text { May })+ \\
\quad 0.77 \Delta P_{r e}(\text { Aug })-0.24 \Delta H_{u m}(\text { May })-0.31 \Delta H_{u m}(\text { June })-0.29 \Delta H_{u m}(\text { Aug })\end{array}$ & 0.84 & 130.2 & $<0.0001$ \\
\hline Mirpur Khas & $\begin{array}{c}\Delta Y=0.25 \Delta T_{\max }(\text { July })+0.47 \Delta T_{\min }(\text { May })+0.46 \Delta T_{\min }(\text { July })-0.59 \Delta T_{\min }(\mathrm{Sep})+ \\
0.59 \Delta S_{u n}(\text { May })-0.30 \Delta S_{u n}(\text { Aug })-0.21 \Delta H_{u m}(\text { Aug })\end{array}$ & 0.87 & 104 & $<0.0001$ \\
\hline Rahim Yar Khan & $\begin{array}{c}\Delta Y=-1.04 \Delta T_{\min }(\text { May })+1.98 \Delta T_{\min }(\text { July })-0.70 \Delta T_{\text {ave }}(\text { Aug })-0.85 \Delta P_{r e}(\text { Aug })+ \\
0.53 \Delta S_{u n}(\text { July })+0.82 \Delta H_{u m}(\text { May })+0.78 \Delta H_{u m}(\text { July })\end{array}$ & 0.53 & 75.1 & 0.003 \\
\hline Rajanpur & $\begin{array}{c}\Delta Y=0.41 \Delta T_{\max }(\text { July })+0.96 \Delta T_{\min }(\text { Aug })-0.61 \Delta T_{\text {ave }}(\text { Aug })+0.52 \Delta S_{u n}(\text { Sep })+ \\
0.41 \Delta H_{u m}(\text { June })+0.79 \Delta H_{u m}(\text { Sep })\end{array}$ & 0.62 & 61.1 & $<0.0001$ \\
\hline Bahawalpur & $\begin{array}{c}\Delta Y=2.1 \Delta T_{\max }(\text { May })+0.54 \Delta T_{\max }(\text { July })+2.9 \Delta T_{\min }(\text { May })-3.97 \Delta T_{\text {ave }}(\text { May })- \\
0.46 \Delta P_{r e}(\operatorname{Sep})+0.84 \Delta S_{u m}(\operatorname{Sep})+0.54 \Delta H_{u m}(\text { June })+0.53 \Delta H_{u m}(\text { Aug })+0.62 \Delta H_{u m}(\text { Sep })\end{array}$ & 0.77 & 57.1 & $<0.0001$ \\
\hline Bahawalnagar & $\Delta Y=-1.51 \Delta T_{\max }($ June $)-1.28 \Delta T_{\min }($ June $)+0.57 \Delta T_{\min }($ July $)+1.53 \Delta T_{\text {ave }}($ June $)$ & 0.63 & 77.3 & 0.014 \\
\hline Multan & $\begin{aligned} \Delta Y= & -1.1 \Delta T_{\max }(\text { June })+0.98 \Delta T_{\max }(\text { July })+0.61 \Delta T_{\text {ave }}(\text { June })-0.36 \Delta S_{u n}(\text { June })+ \\
& 0.33 \Delta S_{u n}(\text { Sep })-0.55 \Delta H_{u m}(\text { July })-0.35 \Delta H_{u m}(\text { Aug })+0.71 \Delta H_{u m}(\text { Sep })\end{aligned}$ & 0.75 & 78.2 & 0.001 \\
\hline Vehari & $\Delta Y=0.85 \Delta T_{\min }($ June $)-1.94 \Delta T_{\min }($ July $)+1.78 \Delta T_{\text {ave }}($ July $)-0.93 \Delta H_{u m}($ Aug $)+0.67 \Delta H_{u m}($ Sep $)$ & 0.65 & 86.2 & 0.002 \\
\hline Sahiwal & $\Delta Y=0.86 \Delta T_{\min }($ June $)-0.96 \Delta T_{\min }($ July $)+1.16 \Delta T_{\text {ave }}($ July $)+0.55 \Delta S_{u n}($ July $)+0.66 \Delta H_{u m}($ July $)$ & 0.34 & 123.1 & 0.04 \\
\hline Jhang & $\Delta Y=0.56 \Delta T_{\max }($ July $)+0.49 \Delta T_{\min }($ June $)+0.41 \Delta P_{r e}(\mathrm{Sep})+0.83 \Delta S_{u n}($ July $)$ & 0.47 & 92.4 & 0.003 \\
\hline
\end{tabular}




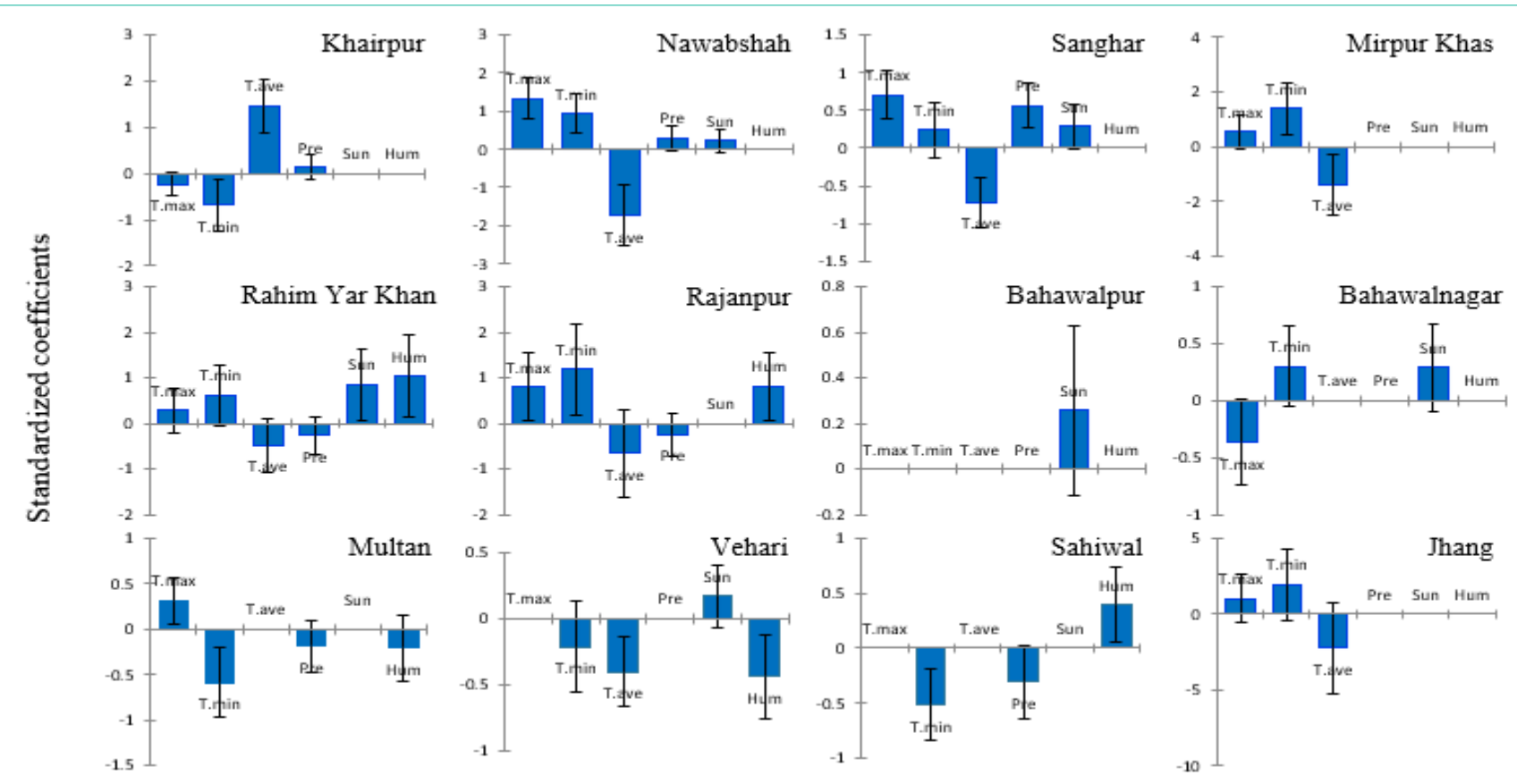

Climate Variables

Figure 5: Bar chart of climate variables linear regressed on cotton yield $(\mathrm{kg} / \mathrm{h})$ blue bar show standardized coefficients, which are statistically significant at the $5 \%$ level of significance.

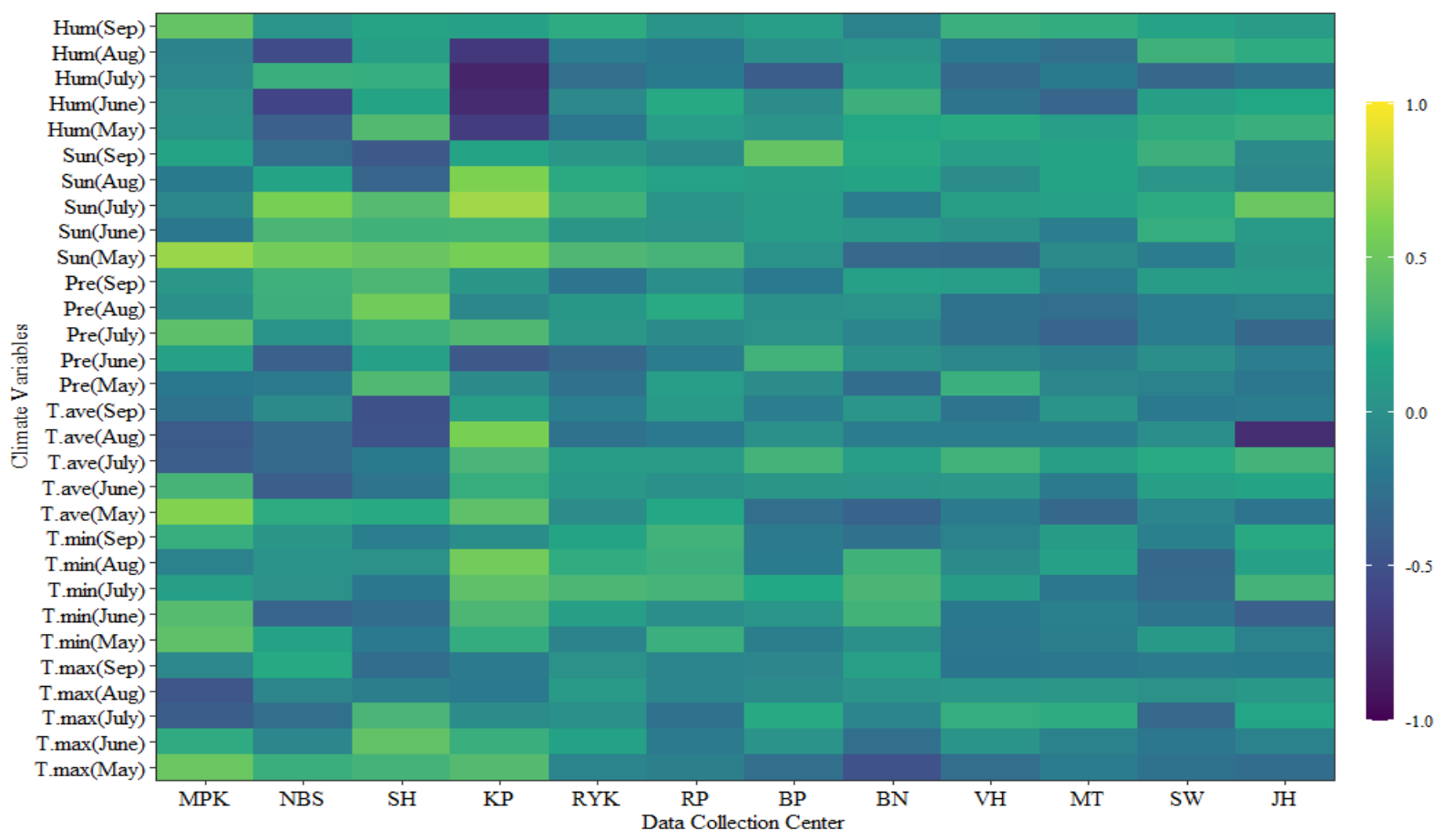

Figure 6: Pearson's correlation coefficients between the cotton crop yield and the month-wise climate variables from $1989-2018$ at 12 sites in the Indus River basin, Pakistan.

cultivated area from North to South of the Indus River basin.

Both statistically positive and negative relations between crop yield and climate were observed. Lobell et al. [48] used Pearson's method to study the relationship between wheat yield and $\left(T_{\max }, T_{\min }\right.$ and $S_{u n}$ ) in two main areas of wheat production from 1988 to 2002 in Mexico. They found that climatic trends $\left(T_{\max }, T_{\min }\right.$ and $\left.S_{u n}\right)$ described $72 \%$ and $66 \%$ of the wheat yield in the two different study areas. There was a significant negative correlation between $T_{\min }$ and wheat 
yield, while $T_{\max }$ and $S_{u n}$ were insignificantly correlated with wheat yield. However, in this study cotton yield is positively correlated with $S_{u n}$ while it shows a significantly negative relation with $\left(H_{u m}\right.$, $\left.T_{\max }\right)$. Prabnakorn et al. [55] applied Pearson's method to examine the association among climatic variables $\left(T_{\max }, T_{\min }\right.$, and $\left.P_{r e}\right)$ and rice yield in the Mun River Basin region of Thailand from 1984 to 2013. They found the variations in climatic trends could describe 22$37 \%$ of the variations in yields of rice. Rice yields were found more sensitive to $T_{\min }$ than $T_{\max }$ and showed negatively correlated with an increase $T_{\min }$ [55]. We also found that yield is more sensitive to the alteration in $T_{\min }$ and $H_{u m}$ as compared to other climate trends. With the increase of each $100 \mathrm{~mm}$ in $\mathrm{P}_{\mathrm{re}}$, yield increased by 0 to $8.9 \%$ [34]. The correlations among $\mathrm{P}_{\mathrm{re}}$ and cotton indicators were not significant at most of the spots, and it may be due to the fact that in the past 30 years, precipitation during the cotton-growing period showed no clear trends in most areas of the Indus River basin cotton belt. Moreover, the Indus River basin cotton belt is in the semi-arid and arid zone, agriculture is mostly dependent on irrigation system, and the influence of precipitation on cotton yield was insignificant.

Cotton yield and climatic variables are considered as the dependent and independent variables respectively were analyzed by the MLR method. This method is used to estimate of individual influences of every climate variable by capturing the net climate impacts of combined climate variables. Nicholls [45] applied MLR method to examine the effects of Australian wheat against climatic trends in $\left(T_{\max }, T_{\min }\right.$ and $\left.P_{r}\right)$ from 1952 to 1992 and found that these trends seemed to be liable for $30 \%$ to $50 \%$ increase in wheat production, with a rise in $T_{\min }$ being the dominant effect. We noticed that $T_{\min }$ and $S_{u n}$ show a significant positive impact on yield at most sites, but increasing trend in $T_{\min }$ and $H_{u m}$ in main cotton area like Multan and Vehari negatively impact on yield. Chen et al. [34] used MLR method to examine the responses of yield during fluctuations in temperature variance between day and night in three areas (Yangtze River Basin, Yellow River Basin and the Northwest region) of China from 1961 to 2010. They found that temperature had a positive impact on yield in Yellow River Basins and the Northwest. In our results $T_{a v e}$ shows negative impacts on cotton yield, which may be because in our study area cotton is already grown on average at $38^{\circ} \mathrm{C}$ during the growing season. By quantitatively developing the association between crop yield and climate, these studies showed that climatic variables had specific impacts on yield. These results also illustrate that the MLR method captured the relationship between climate variables and cotton yield. However, there was a single climate variable at a few locations, showing a minor impact on yield. This indefinable circumstance implied that climatic variables have the least effect in controlling cotton growth, while some other variables that were ignored in the investigation, such as field management, economic inputs, and other reasons may need to be included. Because of the climatic alterations, the best equations were found as spot specific. Quantitatively, the best equations described the participation of climatic variables in cotton yield prediction. Our findings exhibited site-specific variation in the responses of climate variables on cotton yield in the Indus River basin, Pakistan.

\section{Conclusion}

In this study, we conducted a spatial analysis to examine the trend and the variation in the climate and cotton indices. Our results show that during the past three-decade both climate variables and cotton indices change significantly. Great variations in cotton crop area and yield have been observed at most of the study sites. Temperature and air humidity behave differently at different sites, which assesses the impact of their changing trends on cotton yield. Both positive and negative intersection has been observed at different sites from the statistical results of yield with climate variables. A negative correlation of yield with temperature is found while temperature has an increasing trend in the study area. This suggests that warming temperature in the future could be a great challenge for the cotton crop. The MLR model was used to analyze the impact of climate variables on cotton yield. The regression equations for yield were selected on the basis of $\mathrm{R}^{2}$ adj value which lies between the range of (0.02 - 0.89). It shows the variability of the impact of climate variables on the cotton yield on different sites. It also depicts that at some sites this impact is highly significant. We also analyzed the monthly (MaySeptember) relationship between climate variables and cotton yield. Results show that high temperature and precipitation during May and June, and air relative humidity during July hurting the cotton yield significantly at most of the sites. These results indicated that the cotton yield on the Indus River basin had been significantly impacted by climate change. We can suggest that it is essential to use heatresistant varieties and the adoption of appropriate cotton cultivation culture to mitigate climate change in the future. These results support exploring appropriate agricultural strategies and policies for adapting global climate change in the Indus River basin, Pakistan and the other regions with similar environments and ecological settings.

\section{Acknowledgment}

This research was funded by the National Key Research and Development Program of China, grant number 2017YFA06044033 and 2016YFA0602301, the Joint Fund of National Natural Science Foundation of China, grant number U19A2023. We are also thanks to Nasir Abbas Sipra and Shahbaz Nazir for their help to arrange the data.

\section{References}

1. Akter T, Islam AKMA, Rasul MG, Kundu S, Khalequzzaman Ahmed JU. Evaluation of genetic diversity in short duration cotton (Gossypium hirsutum L.). Journal of Cotton Research. 2019; 2: 1.

2. Alves AN, Souza WSR, Borges DL. Cotton pests classification in field-based images using deep residual networks. Comput Electron Agr. 2020: 174.

3. Chen ZJ, Scheffler BE, Dennis E, Triplett BA, Zhang TZ, Guo WZ, et al. Toward Sequencing cotton (Gossypium) Genomes. Plant Physiol. 2007; 145: 1303-1310.

4. Xun L, Zhang JH, Cao D, Wang JW, Zhang S, Yao FM. Mapping cotton cultivated area combining remote sensing with a fused representation-based classification algorithm. Comput Electron Agr. 2021: 181.

5. Wang HD, Wu LF, Cheng MH, Fan JL, Zhang FC, Zou YF, et al. Coupling effects of water and fertilizer on yield, water and fertilizer use efficiency of drip-fertigated cotton in northern Xinjiang, China. Field Crop Res. 2018; 219 : 169-179.

6. Min L, Geng-xing Z, Yuan-wei Q. Extraction and Monitoring of Cotton Area and Growth Information Using Remote Sensing at Small Scale: A Case Study in Dingzhuang Town of Guangrao County, China, 2011 International Conference on Computer Distributed Control and Intelligent Environmental Monitoring. 2011: 816-823.

7. Cotton I, Change C. Impacts and Options to Mitigate and Adapt. Internationa Trade Centre (ITC): Geneva, Switzerland. 2011. 
8. Beltrão N, Azevedo D. O agronegócio do algodão no Brasil. $2^{\text {nd }}$ edl. rev. ampl. Brasília: EMBRAPA. 2008.

9. Javid K, Akram MAN, Mumtaz M, Siddiqui R. Modeling and mapping of climatic classification of Pakistan by using remote sensing climate compound index (2000 to 2018). Appl Water Sci. 2019; 9: 1-9.

10. Change IC. Synthesis report summary chapter for policymakers. IPCC: Geneva, Switzerland. 2014: 31.

11. Forster P, Ramaswamy V, Artaxo P, Berntsen T, Betts R, Fahey DW, et al Changes in atmospheric constituents and in radiative forcing. Chapter 2 Climate Change 2007. The Physical Science Basis. 2007

12. Giorgi F, Raffaele F, Coppola E. The response of precipitation characteristics to global warming from climate projections. Earth Syst Dynam. 2019; 10: 73 89.

13. Su BD, Huang JL, Gemmer M, Jian DN, Tao H, Jiang T, et al. Statistical downscaling of CMIP5 multi-model ensemble for projected changes of climate in the Indus River Basin. Atmos Res. 2016; 178: 138-149.

14. Du HB, Wu ZF, Li M, Jin YH, Zong SW, Meng XJ. Characteristics of extreme daily minimum and maximum temperature over Northeast China, 1961-2009. Theor Appl Climatol. 2013; 111: 161-171.

15. Ahmad A, Ashfaq M, Rasul G, Wajid SA, Khaliq T, Rasul F, et al. Impact of climate change on the rice-wheat cropping system of Pakistan, Handbook of Climate Change and Agroecosystems: The Agricultural Mode Intercomparison and Improvement Project Integrated Crop and Economic Assessments, Part 2. 2015: 219-258.

16. Nasim W, Belhouchette $H$, Ahmad A, Habib-ur-Rahman M, Jabran K, Ullah $\mathrm{K}$, et al. Modelling climate change impacts and adaptation strategies for sunflower in Pakistan. Outlook Agr. 2016; 45: 39-45.

17. Abbas G, Ahmad S, Ahmad A, Nasim W, Fatima Z, Hussain S, et al. Quantification the impacts of climate change and crop management on phenology of maize-based cropping system in Punjab, Pakistan. Agricultural and Forest Meteorology. 2017; 247: 42-55

18. Qin D, Plattner G, Tignor M, Allen S, Boschung J, Nauels A, et al. Climate change 2013: the physical science basis. Contribution of Working Group I to the Fifth Assessment Report of the Intergovernmental Panel on Climate Change (eds TF Stocker et al.). 2014: 5-14.

19. Rasul F, Gull U, Rahman M, Hussain Q, Chaudhary HJ, Matloob A, et al Biochar an emerging technology for climate change mitigation. J Environ Agric Sci. 2016; 9: 37-43.

20. Bange M, Milroy S. Impact of short-term exposure to cold night temperatures on early development of cotton (Gossypium hirsutum L.). Australian Journal of Agricultural Research. 2004; 55: 655-664.

21. Gwimbi P, Mundoga T. Impact of Climate Change on Cotton Production Under Rain fed Conditions: Case of Gokwe. Journal of Sustainable Development in Africa. 2010; 12: 59-69.

22. Iqbal MA, Ping Q, Abid M, Kazmi SMM, Rizwan M. Assessing risk perceptions and attitude among cotton farmers: A case of Punjab province, Pakistan. International Journal of Disaster Risk Reduction. 2016; 16: 68-74.

23. Luo Q. Temperature thresholds and crop production: a review. Climatic Change. 2011; 109: 583-598.

24. Singh RP, Prasad PV, Sunita K, Giri S, Reddy KR. Influence of high temperature and breeding for heat tolerance in cotton: a review. Advances in Agronomy. 2007; 93: 313-385.

25. Luo Q, Bange M, Clancy L. Cotton crop phenology in a new temperature regime. Ecological Modelling. 2014; 285: 22-29.

26. Rahman MH, Ahmad A, Wang X, Wajid A, Nasim W, Hussain M, et al. Multimodel projections of future climate and climate change impacts uncertainty assessment for cotton production in Pakistan. Agricultural and Forest Meteorology. 2018; 253: 94-113.

27. Fahad S, Bano A. Effect of salicylic acid on physiological and biochemica characterization of maize grown in saline area. Pak J Bot. 2012; 44: 14331438.
28. Reddy KR, Zhao D. Interactive effects of elevated $\mathrm{CO}_{2}$ and potassium deficiency on photosynthesis, growth, and biomass partitioning of cotton. Field Crop Res. 2005; 94: 201-213.

29. Deng Zhenyong, Zhang Qiang, Pu Jinyong, Liu Dexiang, Guo Hui, Wang Quanfu, et al. Impact of climate warming on crop planting and production in Northwest China. Acta Ecologica Sinica. 2008; 28: 3760-3768.

30. Tang Xiang-ling, Xin L. The Relationship between climate change and yield of cotton in Shihezi region. Hubei Agricultural Sciences. 2011; 08.

31. McMichael B, Hesketh J. Field investigations of the response of cotton to water deficits. Field Crop Res. 1982; 5: 319-333.

32. Lamb J, Dowdy R, Anderson J, Rehm G. Spatial and temporal stability of corn grain yields. Journal of Production Agriculture. 1997; 10: 410-414.

33. Huang J, Li J. Effects of climate change on overwintering pupae of the cotton bollworm, Helicoverpa armigera (Hübner) (Lepidoptera: Noctuidae). International journal of biometeorology. 2015; 59: 863-876.

34. Chen C, Pang Y, Pan X, Zhang L. Impacts of climate change on cotton yield in China from 1961 to 2010 based on provincial data. Journal of Meteorological Research. 2015; 29: 515-524.

35. Chaudhary Q, Rasul G. Agro-climatic classification of Pakistan. Sci Vis. 2004; 9: 59-66.

36. Shuli F, Jarwar AH, Wang X, Wang L, Ma Q. Overview of the cotton in Pakistan and its future prospects. Pakistan Journal of Agricultural Research. 2018; 31: 396

37. Nawaz Z, Li X, Chen Y, Guo Y, Wang X, Nawaz N. Temporal and spatia characteristics of precipitation and temperature in Punjab, Pakistan. Water. 2019; 11: 1916.

38. Lobell DB, Cahill KN, Field CB. Historical effects of temperature and precipitation on California crop yields. Climatic change. 2007; 81: 187-203.

39. Yue S, Wang C. The Mann-Kendall test modified by effective sample size to detect trend in serially correlated hydrological series. Water resources management. 2004; 18: 201-218.

40. Kendall M. Rank Correlation Methods, Charles Griffin, London. 1975.

41. Mann HB. Nonparametric tests against trend. Econometrica: Journal of the econometric society. $1945 ; 245-259$.

42. Dindang A, Taat A, Beng P, Alwi AM, Mandai A, Adam S, et al. Statistical and trend analysis of rainfall data in Kuching, Sarawak from 1968-2010. J. Med. Microbiol. 2013; 6: 17.

43. Önöz B, Bayazit M. The power of statistical tests for trend detection. Turkish journal of engineering and environmental sciences. 2003; 27: 247-251.

44. Hirsch RM, Alexander RB, Smith RA. Selection of methods for the detection and estimation of trends in water quality. Water resources research. 1991; 27: 803-813.

45. Nicholls N. Increased Australian wheat yield due to recent climate trends. Nature. 1997; 387: 484-485

46. Bring J. How to standardize regression coefficients. The American Statistician 1994; 48: 209-213.

47. Wang Z, Chen J, Xing F, Han Y, Chen F, Zhang L, et al. Response of cotton phenology to climate change on the North China Plain from 1981 to 2012 Scientific reports. 2017; 7: 1-10.

48. Lobell DB, Ortiz-Monasterio JI, Asner GP, Matson PA, Naylor RL, Falcon WP. Analysis of wheat yield and climatic trends in Mexico. Field Crop Res. 2005; 94: 250-256.

49. Bhatt D, Maskey S, Babel MS, Uhlenbrook S, Prasad KC. Climate trends and impacts on crop production in the Koshi River basin of Nepal. Regional Environmental Change. 2014; 14: 1291-1301.

50. Farkas O, Héberger K. Comparison of ridge regression, partial least-squares, pairwise correlation, forward-and best subset selection methods for prediction of retention indices for aliphatic alcohols. Journal of chemical information and modeling. 2005; 45: 339-346. 
51. Hocking R. Criteria for selection of a subset regression: which one should be used? Technometrics. 1972; 14: 967-976.

52. Garside M. The best sub-set in multiple regression analysis. Journal of the Royal Statistical Society: Series C (Applied Statistics). 1965; 14: 196-200.

53. Haque MM, Rahman A, Hagare D, Chowdhury RK. A comparative assessment of variable selection methods in urban water demand forecasting. Water 2018; 10: 419.

54. Zhang P, Li Y. Study on the Comparisons of the Establishment of Two Mathematical Modeling Methods for Soil Organic Matter Content Based on Spectral Reflectance. Guang pu xue yu Guang pu fen xi= Guang pu. 2016 36: 903-910.

55. Prabnakorn S, Maskey S, Suryadi F, de Fraiture C. Rice yield in response to climate trends and drought index in the Mun River Basin, Thailand. Science of the Total Environment. 2018; 621: 108-119.

56. Wang Z, Wang M, Yin X, Zhang H, Chu Q, Wen X, et al. Spatiotemporal characteristics of heat and rainfall changes in summer maize season under climate change in the North China Plain. Zhongguo Shengtai Nongye Xuebao/Chinese Journal of Eco-Agriculture. 2015; 23: 473-481.

57. Salma S, Rehman S, Shah M. Rainfall trends in different climate zones of Pakistan. Pakistan Journal of Meteorology. 2012: 9.

58. Abbas F. Analysis of a historical (1981-2010) temperature record of the Punjab province of Pakistan. Earth Interactions. 2013; 17: 1-23. 